\title{
Political culture research: dilemmas and trends. Prologue to the special issue
}

\author{
Camelia Florela Voinea ${ }^{1}$
}

Published online: 4 October 2019

(c) Springer Nature B.V. 2019

\begin{abstract}
The democratization waves in central and Eastern Europe, Asia, and Africa touch at the very core of many of our most basic questions about the nature of citizen politics and the working of the political process. [...] The current democratization wave thus provides a virtually unique opportunity to address questions on identity formation, the creation of political cultures (and possibly how cultural inheritances are changed), the establishment of an initial calculus of voting, and the dynamic processes linking political norms and behavior. These questions represent some of the fundamental research issues of our time. The answers will not only explain what has occurred during this democratization wave, but may aid us in better understanding the basic principles of how citizens function within the political process. There has never been a richer opportunity to study the choices of citizens across regime forms and between old and new democracies. The conditions to arrive at a theory of how citizens come to political choices depending on different political settings, and how these choices affect the settings has never been better than today.
\end{abstract}

Russell J. Dalton and Hans-Dieter Klingemann (2007).

\section{The classics and their heritage as suggested by the contemporary trends}

Political Culture Theory has been founded by Gabriel Almond and Sidney Verba in their impressive work, The Civic Culture (1963), and has been viewed ever since as one of the most debated theories in political science whose resilience against devastating criticism has impressed as much the voices defending it as the voices expressing dissatisfaction and doubt. This has resulted in periodically painful or strategic withdrawals from the front, followed by strong comebacks on the arena of political science research. The political phenomena in Eastern Europe after the fall of the iron curtain in 1989 have been giving the latest substantial boosts to political culture research and call it once more to the front. The most powerful argument was the view upon the dynamic role political culture plays in the relationship between the citizens and the State in a democratic society. It was this idea to keep the political culture theory in the spotlight. It still is the idea which shapes the debates and set the trends.

Camelia Florela Voinea

camelia.voinea@fspub.unibuc.ro

1 Department of Political Science, International Relations and Security Studies, European Research Centre for Political Culture, Faculty of Political Science, University of Bucharest, Bucharest,

Romania 
Since the time of its publication in the early 1960s, there has been little change in the classic conceptual backgrounds and architecture of this theory. Rather unevenly, the classic view keeps acquiring relevance and method while the voices emphasizing a missing sound philosophical background become more numerous and stronger as their analyses get into deep. Meanwhile, the culture argument kept the priority, though remained most debated. All this defines what can be called the dilemma in political culture theory. It also emphasizes the political culture research dimensions, and the trends which once in a while get shaped by various conceptual and methodological developments. It is this methodological dimension which draws our attention here.

Methodological approaches on many essential issues in political culture research are developing much faster than the conceptual ones, mainly due to the technological advances, and more often in the connected areas rather than in the original field of political culture theory. The latest developments of these methodological approaches appear as dense, branchy, overwhelming in technical and experimental detail. Though the essential issues remain the same as in the mainstream political culture research, the diversity of research perspectives covering both technological and conceptual aspects make this process appear as lacking direction. In our view, it nevertheless plays a very important role: it makes things move forward toward the philosophical clarifications long awaited by those who expect political culture theory to achieve a scientifically sound status.

There are two essential perspectives which might offer ways to a better understanding of the trends in political culture research:

One appears as a slow process toward the identification of a basic concept. It could be the attitude as in the classic political culture theory. It could be as well some other less sophisticated and more essential concept which could provide a common (ontological) background to the study of the Citizen and the State as bound into a relationship which is fundamental for both. This perspective has been confirmed during the past two decades by the development of the classic political culture theory towards a theory of modernization and human development (Inglehart et al. 2003; Welch 2013) which takes the value as the basic concept in studying the relationship between the citizen and the state and explaining their deeply interrelated dynamics. This perspective seems to show that an ontological clarification of the classic political culture theory should come from the identification of a common conceptual background for both the citizen and the state: from the classic attitude to the value concept. From here we could expect other possible common conceptual backgrounds to be considered, like the emotions (Heaney 2019). Or, perhaps, the meaning, as Luhmann has already suggested not long ago. Though not completely clear from both theoretical and methodological point of view, Luhmann's theory is still very attractive for suggesting the 'meaning' as the most basic concept which could explain the complex dynamics of the citizen, of the state and of their relationship.

Another one appears as a fast process toward the identification of a basic (set of) processes and mechanism(s) which could explain the relationship between the complex dynamics of the citizens and the state as the fundamental parts of a more complex whole. It could be a set of social and political processes and mechanisms which have been and are studied by the classic sciences of sociology, political theory, social and political psychology as well by their interdisciplinary combinations with sciences like economics or anthropology. Though the paradigms have changed from mechanics-inspired to complexity-based, this perspective confirms that the methodological research is currently part of a more comprehensive approach towards an epistemology of political culture aimed at identifying the basic ways in which the citizen and the state work together in a complex relationship which could explain society and polity as well. 
On this latter perspective we have focused our Special Issue with the justifications and goals presented in the following sections.

\section{Political culture theory: the classics}

Almond and Verba's theory of political culture has been strongly influenced by the works of Talcott Parsons (1937, 1951). This explains the focus on the central role norms, values and beliefs are allowed to play in their theory in the relationship between citizens and the State. The conceptual foundation of political culture theory is based on two main components: culture, and empirical data coming from social and political surveys, in particular, attitude surveys.

The way cultural dimension is viewed by its founders acknowledges a psychological perspective based on the ways in which individual citizens internalize the "political system" (i.e., as a whole system, as well as parts of it) in "cognitions, feelings and evaluations" (Almond and Verba 1963: pp. 12-13).

The term 'political culture' thus refers to the specifically political orientationsattitudes toward the political system and its various parts, and attitudes toward the role of the self in the system (p. 12)

The political culture of a nation is the particular distribution of patterns of orientation toward political objects among the members of a nation (p. 13)

(Almond and Verba 1963)

First and foremost, the theory has introduced 'culture' in the fundamental equation of the democratic polity dynamics by interconnecting the citizens and the State in a twoway complex relationship. To this aim, the theory employs two essential concepts: the open polity and the civic culture (Almond and Verba 1963: p. 7). While the concept of 'open polity' is a notion which combines elements from the theories of political economy and democracy, the definition of 'civic culture' is based on the concept of attitude (Allport 1935) whose internal structure provides for the description of a wide range of 'subjective orientations' of the individual citizens toward society, governance and policy, political power and the state.

Secondly, it has employed in a systematic way the empirical support from the public surveys by considering the attitudes measurement as the backgrounds of its methodology.

At the methodological level, social and political psychology as well as anthropology and history have played their role in guiding the choice of the authors. The methodology of attitudes measurement has made possible the study of the nation-wide mass attitudes toward several classes of political objects, like structures and roles, political actors, and policies, decisions and rules (Almond and Verba 1963: p. 14).

In the work of Philipe Converse, published shortly afterwards (1964), attitudes measurements, enriched with measurements concerning political beliefs (ideologies), education and cognitive abilities, were aimed at revealing the factors which are decisive in the formation and change of political preferences, political behaviors, and political participation and implicit in the dynamics of power and stability in democratic environments.

The conceptual and methodological roots of the classic political culture theory should be carefully searched in the earlier developments of social and political research: 
1. Political culture in relation to social context, and cognitive structure (Lazarsfeld et al. 1944; Berelson et al. 1954; Campbell et al. 1960; Campbell 1963)

2. Political culture in relation to the political regime type (democracy) and to the structure (institutional, organizational) and operation of the state (Ellis 1997; Elazar 1970);

3. Political culture in relation to democracy, political power, legitimacy, and trust, especially in the literature on ex-communist societies and the new democracies appeared in the eastern half of Europe after the fall of the iron curtain: Mishler and Pollack (2003), Mishler and Rose (2001), Rose et al. (1998), Rose (1998a, b), Klingemann and Fuchs (1995).

It is worth noticing that along with the experimental research based on analytical techniques and instruments, new research methodologies have been founded on the computational technologies. More sophisticated methodologies were therefore developed and employed in evaluating political attitudes and their dynamics of change ${ }^{1}$ : from information processing (Sullivan et al. 2009) to computational modelling (Taber and Timpone 1996), connectionist modelling (Voinea 2013) to social simulation and simulation-based modelling (Epstein and Axtell 1996). The beginning of this essential scientific endeavor was made by Abelson and Bernstein (1963) and William McPhee and Robert Smith in their early computational and simulation research experiments (McPhee and Smith 1962; McPhee 1971).

\section{The powerful and the weak}

The most powerful argument of the political culture theory was that of placing culture in the relationship between the citizens on the one hand, and the governance, state and political power, on the other hand. The theory was meant to address the democratic societies, their development and stability, and the spread of democracy throughout the world.

What makes this argument most powerful in the political culture theory is the way it addresses the conceptual construction concerning the political role of the individual citizen in a democratic society. It provides support to the idea that individual positions toward political objects-once aggregated in mass attitudes toward governance and state-could influence decisively the dynamics of the state and, eventually, its operation. It could thus induce and enhance major political change phenomena (like political regime changes or revolutions), and, therefore, explain it.

The other argument of the classic political culture theory, the attitude-based methodology, was perhaps not as powerful as the conceptual one, but it was efficient enough as to cover the methodological dimension so as to restrain and tame opposition, disagreement or just doubtful evaluations. We would not be mistaken in reminding that, in the mid 1960s, the attitude theory was in one of its best times after its complicated inception and its fast increasing popularity starting from the 1900s until mid 1930s. ${ }^{2}$ Attitude measurement and survey research were largely the only methodological options for what regards a scientific endeavour which, one might say, has appeared too early in terms of what it got from the

\footnotetext{
${ }_{1}$ For a full description, see: Voinea (2016), Political Attitudes: Computational and Simulation Modelling, Wiley, Chichester, UK.

${ }^{2}$ For a better understanding of the history of the attitude concept and research, see the literature selected and made publicly available by the excellent Mead Project 2.0 at url: <https://brocku.ca/MeadProject/>.
} 
social and political methodology research with respect to what it really offers in terms of the philosophy of science.

Notwithstanding the initially acquired agreement and the high interest shown by many other research communities beside that of political science, what followed to the political culture theory soon after its foundation was to be expected anyway: its arguments-culture, attitudes, and survey data-have found impressive support as well as substantial denial, large acceptance but also strong contestation and rejection, one of the most powerful and complex scientific work of continuity of our times, but also painful stagnation.

Why?-It is hard to offer a global political culture methodological perspective since we are too close and, eventually, part of it. Moreover, we simply are amidst fast-changing, complex facets of the ongoing, often surprizing dynamic development of political culture research. Notwithstanding the 'up-and-downs', critical evaluations have not weaken the wide agreement that culture does matter in the intricate milieu of the two-way dynamic relationships between the citizens and the State. On the contrary, they have directly or indirectly stimulated the development of research in political culture research and connected areas which could provide appropriate support to this idea.

One thing has to be noticed, anyway: it is the research methodology which has been keeping the front page in political culture research for long time. What this actually says it is much more complicated than many agree.

\section{How the powerful turns weak, and the weak turns powerful}

\subsection{Questions to be answered}

In order to understand what makes the arguments 'powerful' or 'weak' in political culture research we should take a closer look to its attribute of influencing the human society from the individual up to the polity level, a basic concept in Almond and Verba's impressive work, The Civic Culture.

What makes culture a powerful argument is how it can provide for the relationship between the State (macro level) and the individual citizens' behaviors and political attitudes (micro level). However, in making this argument effective in political culture research it misses both an operationalization and a method which could enhance the explanatory aims of the micro-to-macro (upward) as well as the macro-to-micro (downward) causality in political change.

Political culture research aims therefore to provide answers to two essential questions:

1. How do the micro-level value systems, belief systems, attitudes and behaviors as well as cognition processes provide for the emergence of political structure at the macro-level? (emergence of structure)

2. How do macro-level political structures and processes reach back to the individual (micro-level) behaviors, values and beliefs, and eventually influence the emergence and dynamics of mass attitudes?(emergence of control, emergence of new order)

If the advanced methodologies of complex systems (Sawyer 2004), social simulation (Gilbert and Troitzsch 2005), artificial societies (Epstein and Axtell 1996), complex adaptive systems (Cederman 1997) or social collective intelligence (Miorandi et al. (2014) provide for substantial solutions to the first type of research questions, the 
second type of research questions is still waiting for a possible answer from political culture theory since it addresses the intermediate role political culture plays between the macro-level and the micro-level of a polity.

On the other hand, what makes the attitude a weak argument resides right in its strongest point, that is, its conceptual structure: the attitude has never been operationalized in its full structural description as it has been defined by Allport (1935). In spite of its complex definition and conceptual structure, attitude operationalization has never reached beyond the definition and operationalization of a binary variable (acceptance/ rejection). It is this fundamental need for considering attitudes' complex structure and dynamics that has substantially influenced the three essential political culture areas of interest which represent our target in this paper:

1. Attitude Measurement Integration of attitude structural components-emotions and affect, values and value systems, beliefs and ideologies, knowledge and cognition, action deliberation - in a fully operational attitude methodology (see Sect. 4.2);

2. Democracy Definition and operationalization of the two-way relationship between citizens and political regime (i.e., democracy, autocracy) in both conceptual and operational terms (see Sect. 4.3);

3. State (Polity) Operationalization of the polity dynamics (see Sect. 4.4).

Individual and mass attitudes, democracy and polity actually constitute the conceptual kernel of the political culture theory. Their incomplete definition and/or operationalization have generated the need to extend the research in various areas from both inside and outside political science so that the missing links-concepts, theories, methodologies-could be brought in and fill the gap. This is the point which needs perhaps more emphasis in order to understand why powerful arguments turn weak and why weak arguments turn powerful in the history of political culture research:

The need to methodologically explore the attitudes in their complex structural description and to achieve operational condition for notions like emotions, values, beliefs, democracy and polity has ultimately "exploded" in an endless chain of research approaches which connect one concept to another, one mechanism to another, one process to another in a round-the-clock running aimed to cover the white spots on the map of the political culture conceptual landscape. It is this part of the internal context of political culture research which guided its development toward extensive methodology research able to sustain theory improvement.

If we take a brief look at the research methodology picture after the political culture theory has been launched, we will notice how the technology innovation has stimulated the avalanche of methodology research directly or indirectly connected to political culture theory. This has met the research developments in many other domains from social and political sciences, and not only. It is this methodology-oriented wave and its impressive breadth which has drawn the eyes on a typical phenomenon for scientific research in general, but atypical as far as it regards the political culture theory: this methodology phenomenon has not appeared at demand, its outcomes are not actually used very much, and moreover, they are poorly assimilated in political culture theory improvement. Political culture theory has remained in its classic mode, while the methodological and theoretical approaches have actually known a rich development. A methodological endeavour of this extent might better support the definition of an epistemology of political culture. However, the huge diversity of issues and their associated methodology makes 
the epistemological step rather difficult. As regards the ontology, it is still waiting for a conceptual clarification.

\subsection{Attitudes}

Since its definition (Allport 1935), the attitude has been operationalized as a binary variable of response (accept/reject). Usually represented as latent variables, attitude as well as its strength has been investigated in social and political attitude survey research with the methodological means offered by correlational and regression techniques, exploratory and confirmatory factor analysis (Pomerantz et al. 1995) or structural equation modelling (SEM) (Judd and Milburn 1980).

Sociology, psychology and social-psychology research on attitudes have been the areas where almost all paradigms have been employed in the operationalization of attitudes: structure of attitudes (McGuire 1968, 1969, 1989, 1993), mathematical-probabilistic formal models of cognitive processing and operational descriptions of attitudes and behavioral control (Fishbein and Ajzen 1975), cognitive modelling (Petty and Cacioppo 1981, 1986; Petty et al. 1995, 2009), and constructivist approaches of the dual model of attitudes (Wilson and Hodges 1992; Wilson et al. 2000) are but few of the approaches which combine two or more structural components of the attitude definition in order to get attitude operationalization. Attitude change research as it has been related to issues like ideology (Duckitt et al. 2002) or persuasion studies (Mutz et al. 1996) have however induced the necessity to adopt a dynamic approach on attitude representation, operationalization and evaluation. The system dynamics paradigm and the differential equation formalism allowed the employment of mathematical modelling in the studies of attitude dynamic change (Levine 2003; Hunter et al. 1972) while multiple concept structures (Dinauer 2009) and multidimensional representations of attitudes and beliefs (Woelfel et al. 1980) allowed for evaluation of their change dynamics. Political attitudes and political cognition approaches concerned with voting behavior and political participation (Lodge and Taber 2005; Kottonau 2002; Kotonau and Pahl-Wostl 2004) have employed the semantic networks methodology (Kim et al. 2009) and agent-based modelling and simulation (Lodge and Taber 2013) and succeeded to operationalize attitudes, beliefs and cognitions in a single framework. Later on, attitude research has employed computational and agent-based simulation modelling methodologies in order to integrate in operational frameworks attitudes with beliefs (Urbig and Malitz 2007; Urbig 2003) or emotions (Brousmiche et al. 2014, 2015, 2016).

Notwithstanding its achievements and performances, political attitude research has still to find solutions for unclear or incompletely specified issues:

Firstly, there is the relationship between the structural components of attitude (Rosenberg and Hovland 1960) which includes values, beliefs, affect (emotions and sentiments), information, knowledge, cognition, behavioural and control issues. Such complex relationship has never been fully integrated in a unified operationalization framework. Self-expression model as defined by Inglehart and Welzel (2005) employs a conceptual model of the relationship between citizens and the state in terms of values, beliefs and attitudes which concern the political regime, its legitimacy, the attitudes toward authority and the support for democracy in a quantitative analytical approach based on survey data. Theories on the universal values and their relationship to beliefs and attitudes (Rokeach 1979; Schwartz 1992) have left incompletely specified the relation between attitudes, values and beliefs and the operationalization of this relationship (Rokeach and Kliejunas 1972; Schwartz and Bardi 1997; Inglehart and Welzel 2005). Left incompletely specified, such relationships 
prevent the attitude modelling research from appropriately capture the complexity and dynamics of attitude formation and change.

Secondly, there is the relationship between macro-level structure and processes, on the one hand, and the formation and change of attitudes, on the other hand. Described in the social action literature as the "downward causation" phenomena (Coleman 1990), the ways in which macro-level structure and processes influence or provide for the formation and influence of individual attitudes and behaviours at the micro-level of society have not been explained so far in political culture conceptual and operational terms. It is one of the strongest challenges faced by political culture theory. Several authors have approached this issue in correlational terms between the trust in democratic institutions and the legitimacy of the democratic institutions in Eastern European post-communist societies (Fuchs 2007), or between trust in institutions and democratic performances of democratic institutions (Klingemann 1999). Though such approaches provide support to the causal explanations of the democratic consolidation in terms of the trust in institutions and their legitimacy, the analyses could not fully explain the formation and change of political attitudes toward democratic institutions, but only take into account the spread of beliefs and, eventually, the strength of the associations between beliefs (trust) and attitudes (accept) in statistical quantifications.

\subsection{Democracy}

Democracy-based research is by far the part of political culture theory which has proved the most substantial change as a cumulated effect of the methodological contributions from political attitude, value, and state (polity) studies.

Almond and Verba addressed the issue of democracy in political culture theory by means of concepts like citizenship, responsibility and responsiveness, administrative and political competence, political elite and leadership.

The research literature on the new democracies in the eastern half of Europe includes a considerable number of studies on the relationship between democracy stability and the political attitudes of citizens in the post-communist societies during periods of transition to democracy (Linz and Stepan 1996) and consolidation of democracy (Merkel 2008; Schmitter and Schneider 2004). The quality of democracy is often studied in relation with the support provided by the citizens to democratic institutions, elections, and political leadership (Klingemann 1999). Studies of political legitimacy, authority and trust have been systematically based on the analysis of citizens' attitudes toward governance, political power and the institutional structure of democratic regimes (Mishler and Rose 2001). A specific approach on democracy in the Eastern European polities after the fall of communism is based on a structural-functional model of simultaneous processes of democracy-building and state-building (Klingemann et al. 2006). The overlapping of these fundamental processes requires for the elaboration of modelling approaches which are able to go beyond the classic functional view. The anticipatory systems might represent a potential development in state studies which could greatly impact the political culture research (see Sect. 6.2).

\subsection{State (polity)}

While political attitude research represents the most advanced part of political culture theory, at least from a methodological point of view, state (polity) research is on the opposite position in the economy of political culture research development. Unclear, contradictory and/or 
incompletely elaborated issues in state theories (Lemay-Hebert 2009, 2013) make difficult (if not impossible) the modelling of the relationship between the citizens and the state.

The methodological roots of political culture research are deeply implanted in the Weberian view of state and its institutional structure (Weber 1949). A relevant positivist approach on state modelling is Easton's political system model (1965) based on system theory. It explains the relationship between citizens' attitudes and the dynamics of democratic state by means of a hierarchical structure of processes which exchange information and employ information processing competences. It is a model of "reactive" systems which tries to accommodate behaviourism, dynamics of attitudes, and information processing, knowledge representation and cognition. However, system theory has been abandoned (Pickel 2007) in favor of state theories based on the methodological individualism (Cederman 1997) or interpretivism (Rhodes and Bevir 2003, 2010). Inspired by the middle-range theory (Merton 1968), Charles Tilly advances theoretical works on state, culture and democracy which assume a dynamic view by taking into consideration dynamic, process-based, context-dependent approaches in modelling state and culture (Tilly 1999), contentious politics and conflict in international relations (Tilly 1978, 2001) or democratization (Tilly 1995, 2001). Agent-based modelling of state (polity) formation, operation and dynamics is based on the methodological individualism paradigm. Methodological approaches of this issue have been extensively elaborated in the area of conflict and international relations (Axelrod 1995; Cederman 1997; Yamakage et al. 2005). Taking as basic examples the state formation and state dynamics in ancient societies and polities (Cioffi-Revilla et al. 2015; Cioffi-Revilla 2001; Cioffi-Revilla and Landman 1999), the approaches on this issue employ agent-based modelling which construct virtual states and provide for various scenarios of war and conflict such that they could approach in a generative manner the state formation and state dynamics. Agent-based models and complex adaptive systems have been employed in state modeling as territorial and economy-based models of the state as actors in a world of state-actors (Cioffi-Revilla and Rouleau 2010; Sakamoto 2013).

One more paradigmatic shift, apparently less effective for quite long, was inspired by Luhmann's work on the autopoietic concept introduced by Maturana (2002). Luhmann suggests that state modelling should be based on the idea of meaning and communication.

Research on meaning construction has been associated with the narratives theories which are mainly concerned with the relationship between collective perceptions and meaning construction, on the one hand, (McBeth et al. 2005), and formation and change of attitudes toward policy at both individual and group or mass level (Narrative Policy Framework, Jones and McBeth 2010).

The paradigmatic changes in what regards state modelling dimension of political culture research has been, on the one hand, the result of the "lack of ontologies and methodologies that are both philosophically profound and scientifically defensible" (Pickel 2007). On the other hand, this repeated paradigmatic shift has also revealed the difficulty of such paradigms in answering one of the most challenging research question which concerns the capacity of political culture theory to explain how order emerges, how macro-level processes and structure (institutions) could influence the micro-level behaviors and interactions?

\section{Ongoing trends}

The explanatory power of the political culture theory resides in employing empirical data and analytical tools in comparative analyses of political participation in various political contexts, political regimes, and countries. From this point of view, the power as well as the 
weakness of the theory resides in the way culture is understood and employed in explaining the relationships between causally related phenomena. As a matter of fact, it was the approach on culture which made the scholars and various research communities raise questions with regard to the soundness of political culture theory (Welch 2013; Mishler and Pollack 2003; Elkins and Simeon 1979) and to its capacity to explain political change (Welch 2013; Steinmetz 1999; Lane 1992; Pye 1973).

Deeply influenced by Parsons' theories on social action, bouncing back and forth between social-psychology and culture theoretical backgrounds (Pateman 1971), and between various schools of methodological individualism (Boudon 1981, 1986), interpretivism (Geertz 1973), or systemism (Pickel 2007; Tilly 1999), political culture theory acquires its explanatory power from a rather structuralist-functionalist view of culture. A positivist account on culture in terms of cultural attributes and their relationships has always been appreciated by the analysists for its capacity to employ substantial empirical means in causality-oriented analysis of variables and mechanisms of political participation. However, it has been harshly questioned and abruptly rejected by those expecting for an operational definition of political culture which could appropriately answer the need to cover the collective nature of culture rather than limiting the theory to an individualist background which atomises the micro-level interaction regardless of its political complexity. This trend has finally induced an increase in the interest focused on the relationship between culture and political science. Late approaches reveal contributions which aim to define what culture is in conceptual and operational terms, and how should culture be related to political participation: ontology and epistemology of political culture (Welch 2013), cultural relativism (Thompson et al. 2006), thick-and-thin neo-cultural synthesis (Mishler and Pollack 2003), to mention but few.

There are two main dimensions of development in political culture research: one consists in the extension of empirical data sources and analytical resources, and the other regards the methodological development especially in connected research areas like political communication, political behaviour, mass attitudes and opinion dynamics. The former represents an extension of the traditional approach of political culture theory toward theories of social change and human development. The latter has surprised and impressed by the massive, intensive research methodology approaches on mechanisms and processes which could explain deep connections between culture and political behaviour, culture and political communication, culture and state formation and state dynamics, etc. The Special Issue is a short but interesting collection of research works which describe in conceptual and technical terms how such mechanisms are identified and linked to theories in psychology and political communication, political leadership and political discourse (see Maertz and Schneider this issue), collective perceptions, opinions and beliefs and political participation (Edmonds this issue), collective perceptions of war and the dynamics of attitudes toward war (Mitsutsuji and Yamakage this issue), collective perceptions, meaning construction and change in the narratives about policies (Smith-Walter et al. this volume), and other issues which could be found in the full list provided in the Editorial of this Special Issue (see Sect. 4). Such mechanisms, as main methodological research targets, are described, tested against empirical data and employed in explaining political culture issues. Beyond this keen research interest for mechanisms and processes as explanatory means based in various (more or less) connected research traditions like social influence, cognitive psychology, economics or governance (policy) research, this type of methodological approaches prove the sustained research interest and theoretical effort toward achieving epistemological backgrounds in political culture theory. Such methodological approaches are but rich and 
competing sources of knowledge and also means of providing ways of defining the type of knowledge they deal with, and the type of cognitions they involve in approaching political culture issues. In other words, most of them are trying to suggest or configure various, competing ways of reaching epistemological backgrounds which might confer soundness to political culture as a theory aimed at relating culture, citizenry and state (polity) dynamics in essential ways. This Special Issue aims at identifying what are the main competing contributions toward achieving a sound epistemological background in political culture theory (see the Editorial Sect. 4).

\subsection{Empirical resources extended}

The main trend in the ongoing political culture research is represented by the extension of empirical data resources and analytical tools. We might distinguish two major dimensions of development: one could be called a "tradition-preserving-and-extending" trend which extends the area of applicability of classic political culture theory toward theories of social change and human development (Inglehart et al. 2003; Inglehart and Welzel 2005). This trend is concerned with the extension of the original work in political culture theory by the development of the most impressive comparative analysis project which has massively extended the work of Almond and Verba to almost all countries in the world and to all political regimes: World Value Survey has been conceived as an overall resource of empirical evidence and analytical capacity developed especially as support for the comparative analysis of as many countries as possible with the explicit goal of identifying the role of political culture in the relationship between people, society, state and governance. This impressive unique resource together with no less relevant and useful developments of the kind like European Social Survey and European Value Study have altogether provided in many respects the necessary support for the aggregation of both empirical data and conceptual work which has finally allowed the employment of political culture theory in updating the theory of human development:

...because of the sheer number of countries for which survey data are available, we are for the first time in the situation to move to the aggregate level of analyses, conducting statistically significant tests of the basic assumption underlying all research into mass belief systems: that variation in these belief systems has a true impact on a society's level of democracy. Aggregate-level analysis of the correlates of democracy was usually left to political economists who could more easily correlate socioeconomic indicators to levels of democracy. But we can now test their models against political culture, examining if socioeconomic factors or features of political culture have a stronger impact on democracy.

(Dalton and Klingemann 2007)

Another impressive data source is the Democracy Barometer which has not only provided sophisticated empirical evidence on the new democracies appeared in the eastern half of Europe after the fall of the Berlin Wall, it has moreover served as a means to develop new theory with regard to the relationship between citizens preferences, expectations and actions, on the one hand, and democracy legitimacy, efficiency, and stability, on the other hand: 
... the $\mathrm{D}$ [emocracy] $\mathrm{B}$ [arometer] consists of a total of 100 indicators selected from a large collection of secondary data (p. 9)

... reflects the idea that democracy should be seen as a political system which continuously redefines and alters itself depending on ongoing political as well as societal deliberation (p. 9)

... The main aim of the DB is to describe different profiles of democracy (p. 10)

(Buhlmann et al. 2011)

\subsection{Methodology reloaded}

Beside this powerful trend toward empirical resource extension and advanced analytic methods, there is a persistent methodology trend which characterizes many areas connected to political culture research. This trend emphasizes the relevance of methodology research based on the advanced technologies of the artificial.

Classic political culture research has been initially developed by its founders as comparative analysis research at country-level. Its classic methodological approach is based on attitude measurements and analyses. While considered as providing essential support by its founders, attitude measurement has been considered by others (Welch 2013) as the main obstacle in the conceptual and theoretical development of political culture as area of research. One might argue, however, that it was not the only one.

The empirical measurement of citizens' political attitudes toward policy, state and society was a basic brick in this theoretical construction, but it was just one of many other necessary bricks. It is their tied relationship to political attitudes as well as their very complexity which actually keep political culture theory "imprisoned" in a very much constraining bounding. If we speak about empirical measurement of the connection between the individual citizen and the state, then we have at least three other major problems of measurement: one is "political power", the other one is "emotion", and still another is the "polity" itself.

Attitude research methodologies have evolved from the classic empirical measurement methods toward dynamic, computational and simulation-based methods which allow for advanced approaches on attitude formation and attitude change dynamics. Attitude research has emphasized systematic paradigmatic shifts in a quite short time from the classic variable-based measurement and survey analysis to (1) mathematical modelling and differential equations, (2) system dynamics, (3) computational modelling, (4) agent-based modelling, and (5) big-data and web-based semantics modelling (Voinea 2014, 2016).

However, the search for methodological backgrounds has currently reached far beyond the classic methodological kernel of attitude measurement and analysis. The "boom" of methodological research development which started immediately after the 1960s has revealed the fundamental methodological necessity to include measurement theories and measurement systems as well as complexity measurement and evaluative means for multiple other dimensions, like (1) values (Schwartz 2012), (2) beliefs and ideologies (Jost et al. 2008), (3) emotional phenomenology including that which emerges on the socializing networks and virtual platforms, (4) political power, (5) political regime and political structure, (6) polity, and least but not last, (7) international relation context-dependency of the relationship between the individual citizens' attitudes and the state. This impressive methodological research endeavour which lasts for almost one century has configured a 
methodological "landscape" with two fundamental characteristics which might decisively impact the future evolution of the political culture theory.

Firstly, this methodological landscape looks like it is continuously expanding and diversifying by employing methodological theories and techniques from connected research areas, like social simulation, computational linguistics, narratives, content analysis, web semantics, data mining and machine learning, to mention but few. This "all-inclusive" tendency requires philosophical backgrounds, conceptual clarifications. However, what is relevant from a methodological point of view, it increases the complexity of research approaches in political culture theory. Increased complexity might be or might be not an advantage unless the advanced technologies provide their continuous support to methodological adaptive and innovative processes. This actually creates a "feed-forward" cycle between methodology and theory which emphasizes a crisis between them in political culture since the theory does not acquire support for conceptual innovation notwithstanding substantial and almost overwhelming methodological researches which (directly or indirectly) concerns it.

Secondly, this extensive and impressive methodological development induces a fragmentation of the research domain into niche areas. The problem of fragmentation is that after intensive research and development, their aggregation back into the initial domain might have unexpected consequences, including that of lack of conceptual coherence, ultimately producing separate theories which cannot or could hardly exchange or improve on each other. The ongoing situation reveals several major theoretical developments which appear as separate research endeavours and allow for drawing specific conclusions:

One is the value-based approach on political culture (Inglehart 1990, 1997; Inglehart and Welzel 2005; Inglehart et al. 2003).

Others are concerned with democracy and democratic regimes and include approaches which combine state-building with democracy-building (Klingemann and Fuchs 1995; Fuchs 2007) and approaches on the structure and functionalities of democratic regimes in terms of basic democratic processes: Merkel's model of defective democracy (Merkel 2004) includes a number of processes which are considered essential for the democracy definition and operation, and which interact with each other while keeping a certain degree of independence.

Still others are concerned with state (polity) and political power. The approaches which try to combine them with political culture theory reveal various problems, most of them addressing the methodological issues: state formation and state dynamics (Steinmetz 1999; Tilly 1999), state performance in terms of governance and/or political regime (Marsh 2011, Rhodes and Bevir 2010), political power (Favre et al. 2019).

\section{Future lines of development and their possible justification}

The apparently parallel evolutions of the fast, substantial, relevant research methodology developments, on the one hand, and of the rather slow epistemological and ontological clarifications, on the other hand, inform a thick process of exploratory research aimed at political culture theory improvement. However, the difference in the pace of development proves that research is still far from reaching such clarifications.

There are certain aspects which should be emphasized with respect to potential evolutions in political culture theory and research. This might help us understand why from the methodological perspective we see an overwhelming development (with potential relevant 
epistemological consequences) in sharp comparison with the slowness of change on the ontological dimension where the notion of "subjective orientations" is still in place.

The conceptual arguments we take into consideration in making preliminary evaluations are the attitudes, the state (polity) and the relationship between their dynamics - the essential concepts of the classic political culture theory. In what regards methodologies, we are concerned with measurement and modelling, following the goal of explanation if the perspective remains the classic one: causality. However, one cannot avoid taking into account the complexity of the political culture concept and therefore it might be useful to take a brief look at both experimental political science area, which is mainly concerned with empirical data, and at virtual experiments (Bond et al. 2012), and simulation-based modelling research as solutions based on generative data and, eventually, reliable testing against empirical data (Flache et al. 2017).

In this context, the aspects of potential future developments of political culture theory which deserve careful evaluation are: (1) attitudes, values, beliefs, emotions and behaviours in relation to political power and polity dynamics, (2) meaning in relation to political power and polity dynamics, (3) reflexive systems and reflexivity on the internet.

In order to understand why these dimensions of study could be worth developing we should recall the basic concept of the classic political culture theory: the attitude.

After the fall of communism in Eastern Europe in 1989, political culture theory had a strong comeback which has been very much facilitated by the need to explain the revolutions, the emergence of the new democracies, and whether the new democratic regimes could achieve and preserve political stability. The interest in political culture-based explanations of the third wave of democratization (Huntington 1993) has emphasized a revived interest for value theories such that the approach based on value theory has soon become the dominant view in political culture research. Following the works of Milton Rokeach who defines values as "enduring beliefs", and value systems as "enduring organization of beliefs" (Rokeach 1979: p. 5), the value-based approaches on democracy and democratization processes in the Eastern European countries in the 1990s provided for a more comprehensible type of cross-country comparative analysis than that based on attitudes in classic political culture theory. From this point of view, political culture research employs the values as basic terms of analysis and explanation, since they are considered the attitudes' structural determinants. Causality-based explanation shifts, therefore, its focus on values, which take a position of precedence with respect to attitudes dynamics, achieving explanatory power of (mass) attitudes' change in terms of values' change. Moreover, the relationship between citizens' attitudes and state dynamics is also described in terms of values. This view has become dominant in the modernization and human development theory which take political culture theory as background (Inglehart and Welzel 2005). This constitutes a good example of how epistemological focus of political culture theory shifts from attitudes as operational definitions of the "subjective orientations" to values, that is, from their most unstable (attitude) to their most stable locus (values). This proves that, for causal explanation purposes and in spite of its focus on the individual level, political culture theory needs to refine its conceptual basis such that it can identify the universal aspects rather than capture the individual differences in the relationship between the citizen and the State. From this perspective, the selection of the unit of comparison in comparative analysis might go on identifying any of the structural determinants of the attitudes which might be considered as the locus of subjective orientations. The interesting research question here is where should this selection stop?-Several answers have been already investigated, like emotions, certain beliefs or specific (kind of) knowledge. This, however, would 
not solve the fundamental problem, which is that of explaining if and how mass attitudes could provide for dynamic change in the (democratic) polity operation.

At this point, it is important to emphasize that the "subjective orientations" could be successfully replaced in the conceptual background of political culture theory by a different view on the concepts which could serve the goal of revealing how the relationship between the citizenry and the state actually works. Both need a different modelling approach, and this could be decisive for political culture theory in achieving explanatory power, and sound ontological and epistemological background.

Meaning, as Niklas Luhmann claims (2012), is what people as well as institutions actually exchange in their communication and interactions. Reflexive systems are systems with internal model-based behaviour (Rosen 1985), that is, systems which adapt by employing their internal model in operating changes on themselves (Dubois 1998). Reflexivity of virtual agents in social media, no matter how simple or complex they are, represents the attribute of being able to receive, understand and re-transmit meanings of the messages they exchange with other virtual agents of the same or of different kind. These aspects represent as many directions of further developments in political culture research because they offer solutions to the classic problem of explaining if and how can citizens influence polity dynamics. For the purpose of explaining all this, one needs to differently model both the individuals' interactions with the polity as well as the polity itself. This might need to replace the concept of "subjective orientations" with another one which could be identified in both individuals and the state, and to appropriately model the state. Reflexive modelling provides for definition of state dynamics in terms of state own capabilities to change by changing itself.

In political culture-connected areas of research, the need to address the issue of meaning formation and change is related to governance and the theories and methodologies of narratives. Reflexivity has been addressed in ways which are deeply relating it to the issues of state dynamics, collective perceptions formation and change, social media and web platforms and their impact on society and polity dynamics. Complexity has been already associated with most advanced studies of political interaction and political participation, to mention but very few.

\subsection{Where are dilemmas coming from?}

There are two main targets of huge interest which generate dilemmas, and induce sensitivity in the trends. In other words, two main issues which draw the eyes on political culture theory: citizens' attitudes and the state (polity).

Attitude as a choice for the methodological background of the theory might be questioned with regard to two aspects:

One is the aspect of its full operationalization with respect to the classic conceptual definition. Operationalization is important as it allows the attitude modelling with advanced simulation modelling techniques. Lacking an operationalization of its conceptual structure and of the complexity of its internal structural relationships, attitude measurement might inform differently a relationship between citizens and the state, while attitude dynamics might perform differently in a modelling approach. This difference could be decisive for the relevance of the attitude as the basis of an ontological choice. So far, attitudes are a complex but efficient substitute for the subjective orientations, which are in turn a substitute for a sound ontological solution. However, the theoretical and methodological research developments on structural issues of attitudes and their relations, like emotions 
and cognitions, prove that attitudes are but one level of meaning construction and change which might be either too high (complex) or two low (elementary) in a meaning generative organization to remain the final choice for a political culture operationalization aimed at explaining how political culture works with respect to the relationship between the citizens and the state, and eventually with respect to political change.

Another aspect addresses the possible relations between levels of reality (Poli 2001, 2006). Political culture actually works with a whole hierarchy of concepts from individual to collective perceptions to mass attitudes (and the intermediate levels might be much more complex than we expect), each requiring or constructing or projecting on a different level of reality. The experimental workings or simulations of a model of the complex two-way relationship between the citizens and the state should take into consideration the possible relations between levels of reality since the citizens might differ in their political participation capacity also due to such conditioning.

On the other hand, it would be worth taking the other perspective on political culture theory and its explanatory claims: the state (polity) perspective. The problem of how the state could ultimately influence the citizens' attitudes is what makes it worth developing as a fundamental research issue. Culture has been viewed as a means of control exerted from macro-structures to the individual level of society (micro-level) (Elkins and Simeon 1979). However, before addressing the ways in which state dynamics could inform and eventually influence the individuals' subjective orientations, the formation and change of collective perceptions and the emergence of mass attitudes, which is how the control problem has been formulated so far, there is a different way to formulate the issue, namely, subsuming a control issue to an operational issue, and thus making the control dimension belong to the state's endogenous space. This turns the issue of the control a polity might have on the societal level into an issue of polity operation and polity dynamics. To this end, a polity model might be necessary to simulate the complexity of social-political systems. In Sect. 4.4, we have summarized a collection of paradigmatic approaches to this issue. The general difficulty which they encounter arises from employing modelling methodologies which do not achieve the dynamics of a complex polity, but rather the dynamics of a structural-functional polity, which is not quite the same. It is this special matter which made many remind of Luhmann's idea about how the state might operate. It is the idea of a beautiful mind. However, it needs to get effective.

To this aim, the brief discussion below makes reference to three interesting approaches: (1) meaning construction and meaning communication as the means of state operation, (2) reflexivity of virtual systems, and the methods employed to achieve reflexivity in the web space, and (3) anticipatory systems.

\subsection{Brief discussion}

There are some attractive developments which might radically change the classic view on culture, citizens and the state. They include at least three relevant ideas: the theory of meaning and communication (Luhmann 1995, 2012), the anticipatory systems and their possible application to polity modelling (Leydesdorff 2003; Leydersdorff and Dubois 2004; Dubois 1998) or qualitative approaches to political anticipation (Caillol 2017), and the methodologies which provide for the explanation of the relationship between virtual worlds, that is, internet and the socializing networks, and the real world, that is, citizen, state, governance. 
Luhmann's approach on the political system (2012) is based on the concept of autopoietic system, that is, a reflexive system in which communication and meaning construction are essential for the operation of the state (polity). Anticipatory approach is based on the idea that the system contains a model of itself which is employed in constructing alternatives of meaning and in choice making.

The anticipatory systems could bring a radical paradigmatic change in state modelling research: they provide for a different definition of the state (polity) systems as systems which embed models of themselves, that is, reflexive systems. This would not eliminate the difficulties in approaching the polity modelling complexity, on the contrary, it is the complexity which could be more appropriately approached in this paradigm. Introduced by Rosen (1985), the reflexive models have been formalized by Dubois (1998) by introducing the mathematical notions of incursion and hyperincursion in order to define the two types of systems with reflexive capacities. Anticipatory modelling of state (polity) might be able to answer the question regarding the influence propagated from the macro-level (polity processes and structures) to the individual level (micro-level) of society (Leydesdorff 2003).

The research methodologies which provide support for a better understanding of the impact the virtual worlds and communication have onto the real world and citizens are based on theories in physics and biology which have been adapted for the study of human societies and radical political change phenomena, like revolutions. One example of such methodology is the research on revolutions and society collapse based on self-organized critical systems (Brunk 2001, 2002). Self-organized criticality is a phenomenon in nonequilibrium physical systems, which has been applied to the study of human society, more precisely, to the socializing networks communication phenomenology. It is often connected with the reflexivity virtual systems might acquire in studies of the socializing networks and how can their phenomenology be connected to collective action, social mobilization or revolution.

\subsection{A matter of approach}

Now-a-days, empirical data is provided in sophisticated patterns and huge amounts by different types of social media, like the socializing networks or virtual platforms, like the web forums. The consequences of this uncommon development in research methodologies would soon have an impact on the needs for identifying solid ontological and epistemological grounds in the political culture theory.

Notwithstanding the uneasiness such a methodological "rolling stone" might induce in the methodological habits, skills or preferences of political culture students, the widely extending research issues, outcomes and performances would seriously questions the ability of political culture theory to adapt to technological and methodological innovation challenges. Some authors raise high expectations from the methodological changes:

What seems to be clear then is that the syndrome of self-expression values is of major importance. What is not exactly clear, though, is how these values translate into behavior. The precise micro-level mechanism of how self-expression values create certain forms of elite-challenging activities is unobserved so far and it is also not known how these activities aggregate into the mass-level patterns that have been shown to work so strongly in favor of democracy. Future research should work on these research gaps.

(Welzel 2009: p. 315) 
Many others, more skeptical, dismiss the value of the methodological innovation offered by computational and agent-based simulation methodologies while keeping more confident in classic empirical analytical methodologies.

The Special Issue on Political Culture Research Methodologies is meant to emphasize the ever expanding methodological development and its diversity of orientations, to warn on some methodological orientations and developments which should be taken into consideration for their consequences on an epistemology of political culture theory.

\section{References}

Abelson, R.P., Bernstein, A.: A computer simulation model of community referendum controversies. Public Opin Q 27(1), 93-122 (1963)

Allport, G.W.: Attitudes. In: Murchison, C. (ed.) Handbook of Social Psychology, pp. 798-844. Clark University Press, Worcester (1935)

Almond, G.A., Verba, S.: The Civic Culture: Political Attitudes and Democracy in Five Nations, Abridged ed. Sage, London ([1963] 1989)

Axelrod, R.: Building new political actors: a model for the emergence of new political actors. In: Gilbert, N., Conte, R. (eds.) Artificial Societies: The Computer Simulation of Social Life. University College Press, London (1995)

Berelson, B., Lazarsfeld, P.F., McPhee, W.N.: Voting: A Study of Opinion Formation in a Presidential Campaign. Chicago University Press, Chicago (1954)

Bond, R.M., Fariss, C.J., Jones, J.J., Kramer, A.D.I., Marlow, C., Settle, J.E., Fowler, J.H.: A 61-millionperson experiment in social influence and political mobilization. Nature 489, 295-298 (2012)

Boudon, R.: The Logic of Social Action. Routledge, London (1981)

Boudon, R.: Theories of Social Change. University of California Press, Berkeley (1986)

Brousmiche, K.-L., Kant, J.-D., Sabouret, N., Prenot-Guinard, F., Fournier, S.: The role of emotions on communication and attitude dynamics: an agent-based approach. In: Conference Paper, Conference: WCSS, Sao Paulo, November 2014 (2014). https://www.researchgate.net/publication/268148389_ The_role_of_emotions_on_communication_and_attitude_dynamics_an_agent-based_approach

Brousmiche, K.-L., Kant, J.-D., Sabouret, N., Prenot-Guinard, F., Fournier, S.: From field data to attitude formation. In: International Conference on Advances in Social Simulation 2015, ESSA, Sep 2015, Groningen, pp. 1-14 (2015)

Brousmiche, K.-L., Kant, J.-D., Sabouret, N., Prenot-Guinard, F.: From beliefs to attitudes: polias, a model of attitude dynamics based on cognitive modelling and field data. J. Artif. Soc. Soc. Simul. 19(4), 2 (2016)

Brunk, G.G.: Self-organized criticality: a new theory of political behaviour and some of its implications. Br. J. Polit. Sci. 31(2), 427-445 (2001)

Brunk, G.G.: Why do societies collapse? A theory based on self-organized criticality. J. Theor. Polit. 14(2), 195-230 (2002)

Buhlmann, M., Merkel, W., Muller, L., Wessels, B.: the democracy barometer: a new instrument to measure the quality of democracy and its potential for comparative research. Eur. Polit. Sci. 11, 519-536 (2011)

Caillol, M.-H.: Political anticipation of global systemic crisis \#060. Posted on Sep 21, 2017 by Guadalajara Geopolitics Institute in Podcast, Geopolitics \& Empire (2017)

Campbell, A., Converse, P.E., Miller, W.E., Stokes, D.E.: The American Voter. Wiley, Oxford (1960)

Campbell, D.T.: Social attitudes and other acquired behavioural dispositions. In: Koch, S. (ed.) Psychology: A Study of a Science, vol. 6, pp. 94-172. McGraw-Hill, New York (1963)

Cederman, L.-E.: Emergent Actors in World Politics: How States and Nations Develop and Dissolve. Princeton University Press, Princeton (1997)

Cioffi-Revilla, C.: Origins of the international system: mesopotamian and West Asian polities, 6000 B.C. to 1500 B.C. In: Annual Meeting of the ASOR (2001)

Cioffi-Revilla, C., Landman, T.: Evolution of maya polities in the ancient mesoamerican system. Int. Stud. Q. 43(4), 559-598 (1999)

Cioffi-Revilla, C., Rouleau, M.: MASON RebeLand: an agent-based model of politics, environment, and insurgency. Int. Stud. Rev. 12, 31-52 (2010) 
Cioffi-Revilla, C., Honeychurch, W., Rogers, J.D.: MASON hierarchies: a long-range agent model of power, conflict, and environment in inner Asia. In: Bemmann, J. (ed.) Complexity of Interaction Along the Eurasian Steppe Zone in the First Millennium. Bonn Contributions to Asian Archaeology Volume 7, Vor- und Fruhgeschichtliche Archaologie, Rheinische Friedrich-Wilhelms-Universitat Bonn (2015)

Coleman, J.S.: Foundations of Social Theory. Harvard University Press, Cambridge (1990)

Converse, P.E.: The nature of belief systems in mass publics (1964). Crit. Rev. J. Polit. Soc. 18(1-3), 1-74 (1964)

Dalton, R.J., Klingemann, H.D.: Citizens and political behavior, introduction. In: Dalton, R.J., Klingemann, H.D. (eds.) The Oxford Handbook of Political Behavior. Oxford University Press, Oxford (2007)

Dinauer, L.D.: Toward a more comprehensive theory of attitude change: the effects of inter-attitudinal concept structure on attitude dynamics. Adv. Consum. Res. 36, 621-622 (2009)

Dubois, D.M.: Computing anticipatory systems with incursion and hyperincursion. In: Computing Anticipatory Systems: CASYS-First International Conference, AIP Conference Proceedings, vol. 437. The American Institute of Physics, pp. 3-29 (1998)

Duckitt, J., Wagner, C., du Plessis, I., Birum, I.: The psychological bases of ideology and prejudice: testing a dual-process model. J. Pers. Soc. Psychol. 83, 75-93 (2002)

Easton, D.: A Systems Analysis of Political Life. University of Chicago Press, Chicago (1965)

Elazar, D.J.: Cities of the Prairie: The Metropolitan Frontier and American Politics. Basic Books, New York (1970)

Elkins, D.J., Simeon, R.: A cause in search of its effects, or what does political culture explain. Comp. Polit 11, 127-145 (1979)

Ellis, R.J.: American Political Cultures. Oxford University Press, New York (1997)

Epstein, J.M., Axtell, R.L.: Growing Artificial Societies: Social Science from the Bottom Up. MIT Press, Cambridge (1996)

Favre, M., Swedlow, B., Verweij, M.: A cultural theory and model of power relations. J. Polit. Power 12(2), 245-275 (2019)

Fishbein, M., Ajzen, I.: Belief, Altitude, Intention, and Behavior. Addison-Wesley, Reading (1975)

Flache, A., Mäs, M., Feliciani, T., Chattoe-Brown, E., Deffuant, G., Huet, S., Lorenz, J.: Models of social influence: towards the next frontiers. J. Artif. Soc. Soc. Simul. 20(4), 2 (2017)

Fuchs, D.: The political culture paradigm. In: Dalton, R.J., Klingemann, H.D. (eds.) The Oxford Handbook of Political Behavior. Oxford University Press, Oxford (2007)

Geertz, C.: Thick description: toward an interpretive theory of culture. In: Geertz, C. (ed.) The Interpretation of Cultures: Selected Essays, pp. 3-30. Basic Books, New York (1973)

Gilbert, N.G., Troitzsch, K.G.: Simulation for the Social Scientist, 2nd edn. Open University Press, London (2005)

Heaney, J.G.: Emotion as power: capital and strategy in the field of politics. J. Polit Power. (2019). https:// doi.org/10.1080/2158379X.2019.1618485

Hunter, J.E., Levine, R.L., Sayers, S.E.: Attitude change in hierarchical belief systems and its relationships to persuasibility, dogmatism, and rigidity. Hum. Commun. Res. 3, 3-28 (1972)

Huntington, S.P.: The third wave: democratization in the late twentieth century. University of Oklahoma Press, New Haven (1993)

Inglehart, R.: Culture Shift in Advanced Industrial Society. Princeton University Press, Princeton (1990)

Inglehart, R.: Modernization and Postmodernization: Cultural, Economic, and Political Change in 43 Societies. Princeton University Press, Princeton (1997)

Inglehart, R., Klingemann, H.-D., Welzel, C.: The theory of human development: a cross-cultural analysis. Eur. J. Polit. Res. 42(3), 341-380 (2003)

Inglehart, R., Welzel, C.: Modernization, Culture Change, and Democracy-The Human Development Sequence. Cambridge University Press, Cambridge (2005)

Jones, M.D., McBeth, M.K.: A narrative policy framework: clear enough tobe wrong? The Policy Stud. J. 38(2), 329-353 (2010)

Jost, J., Nosek, B., Gosling, S.: Ideology: its resurgence in social, personality, and political psychology. Perspect. Psychol. Sci. 3, 126-136 (2008)

Judd, C., Milburn, M.: The structure of attitude systems in the general public: comparisons of a structural equation model. Am. Sociol. Rev. 45, 627-643 (1980)

Kim, S., Lodge, M., Taber, C.S.: A computational model of the citizen as motivated reasoner: modeling the dynamics of the 2000 presidential election (October 10, 2008) (2009). Available at SSRN: http://ssrn. com/abstract=1282323 or http://dx.doi.org/10.2139/ssrn.1282323. Accessed 2 Mar 2014

Klingemann, H.D., Fuchs, D. (eds.): Citizens and the State. Oxford University Press, Oxford (1995) 
Klingemann, H.D.: Mapping political support in the 1990s: a global analysis, Chapter 2. In: Norris, P. (ed.) Critical Citizens: Global Support for Democratic Governance, pp. 31-56. Oxford University Press, Oxford (1999)

Klingemann, H.-D., Fuchs, D., Zielonka, J. (eds.): Democracy and Political Culture in Eastern Europe. Routledge, London (2006)

Kottonau, J.: Simulating the formation and change of the strength of political attitudes. Doctoral Dissertation Submitted to the Swiss Federal Institute of Technology Zurich. DISS. ETH NO. 14664 (2002). http://e-collection.library.ethz.ch/eserv/eth:26003/eth-26003-02.pdf. Accessed 30 Apr 2013

Kottonau, J., Pahl-Wostl, C.: Simulating political attitudes and voting behavior. JASSS 7(4) (2004)

Lane, R.: Political culture: residual category or general theory? Comp. Polit. Stud. 25(3), 362-387 (1992)

Lazarsfeld, P.F., Berelson, B., Gaudet, H.: The People's Choice: How the Voter Makes Up his Mind in a Presidential Campaign. Columbia University Press, New York (1944)

Lemay-Hébert, N.: State-building without Nation-building? Legitimacy, state failure and the limits of the institutionalist approach. J. Interv. Statebuilding 3(1), 21-45 (2009)

Lemay-Hebert, N.: Rethinking Weberian approaches to statebuilding. In: Chandler, D., Sisk, T. (eds.) Routledge Handbook on International Statebuilding, pp. 3-14. Routledge, Abingdon (2013)

Levine, R.L.: Models of attitude and belief change from the perspective of system dynamics. In: Paper Presented for the 2003 International System Dynamics Society Conference (2003)

Leydesdorff, L. (2003) Anticipatory systems and the processing of meaning: a simulation using Luhmann's theory of social systems. In: Paper Presented at the European Social Simulation Association (SimSoc VI Workshop), Groningen

Leydesdorff, L., Dubois, D.M.: Anticipation in social systems. J. Comput. Anticip. Syst., Int (2004)

Linz, J.J., Stepan, A.: Problems of Democratic Transition and Consolidation. Southern Europe, South America, and Post-Communist Europe. Johns Hopkins University Press, Baltimore (1996)

Lodge, M., Taber, Ch.S.: The Rationalizing Voter, Cambridge Studies in Public Opinion and Political Psychology. Cambridge University Press (2013)

Lodge, M., Taber, C.S.: The primacy of affect for political candidates, groups, and issues: an experimental test of the hot cognition hypothesis. Polit. Psychol. 26(3), 333-487 (2005)

Luhmann, N.: Social Systems. Stanford University Press, Stanford (1995)

Luhmann, N.: Introduction to Systems Theory. Polity, Cambridge (2012)

Marsh, D.: The new orthodoxy: the differentiated polity model. Public Adm. 89(1), 32-48 (2011)

Maturana, H.: Autopoiesis, structural coupling and cognition: a history of these and other notions in the biology of cognition. Cybern. Hum. Knowing 9(3-4), 5-34 (2002)

McBeth, M.K., Shanahan, E.A., Jones, M.D.: The science of storytelling: measuring policy beliefs in greater yellowstone. Soc. Nat. Resour. 18, 413-429 (2005)

McGuire, W.: The Structure of Individual Attitudes and Attitude Systems, Ch. 3. In: Pratkanis, A.R., Breckler, S.J., Greenwald, A.G. (eds.) Attitude Structure and Function, pp. 37-70. LEA, Hillsdale (1989)

McGuire, W.J.: Personality and susceptibility to social influence. In: Borgotta, E.F., Mabert, W.W. (eds.) Handbook of Personality Theory and Research, pp. 1130-1187. Rand McNally, Chicago (1968)

McGuire, W.J.: The nature of attitudes and attitude change. In: Lindzey, G., Aronson, E. (eds.) The Handbook of Social Psychology, vol. 3, 2nd edn. Addison-Wesley, Reading (1969)

McGuire, W.J.: The poly-psy relationship: three phases of a long affair, Ch. 2. In: Iyengar, S., McGuire, W.J. (eds.) Explorations in Political Psychology, pp. 9-35. Duke University Press, Durham (1993)

McPhee, W.N., Smith, R.B.: A model for analyzing voting systems. In: McPhee, W.N., Glaser, W.A. (eds.) Public Opinion and Congressional Elections, pp. 123-154. Free Press, New York (1962)

McPhee, W.N.: A model simulating voting (with R. Smith and Jack Ferguson). In: Starbuck, W., Dutton, J. (eds.) Computer Simulation of Human Behavior, pp. 469-481. Wiley, New York (1971)

Merkel, W.: Embedded and effective democracies. Democratization 11(5), 33-58 (2004)

Merkel, W.: Plausible theory, unexpected results: the rapid democratic consolidation in central and eastern Europe. IPG No. 2, pp. 11-29 (2008)

Merton, R.: Social Theory and Social Structure (Theories of the Middle-Range). Free Press, New York (1968)

Miorandi, D., Maltese, V., Rovatsos, M., Nijholt, A., Stewart, J. (eds.): Social Collective Intelligence. Combining the Powers of Humans and Machines to Build a Smarter Society. Springer, Basel (2014)

Mishler, W., Rose, R.: Political support for incomplete democracies: realist vs. idealist theories and measures. Int. Polit. Sci. Rev. 22, 303-320 (2001)

Mishler, W., Pollack, D.: On culture thick and thin: toward a neo-cultural synthesis. In: Pollack, D., Jacobs, J. (eds.) Political Culture in Post-Communist Europe, pp. 239-256. Ashgate, London (2003)

Mutz, D.C., Sniderman, P.M., Brody, R.A. (eds.): Political Persuasion and Attitude Change. University of Michigan Press, Ann Arbor (1996) 
Parsons, T.: The Structure of Social Action: A Study in Social Theory with Special Reference to a Group of European Writers. The Free Press, New York ([1937] 1949)

Parsons, T.: The Social System. The Free Press, New York (1951)

Pateman, C.: Political culture, political structure and political change. Br. J. Polit. Sci. 1(3), 291-305 (1971)

Petty, R.E., Cacioppo, J.T.: Attitudes and Persuasion: Classic and Contemporary Approaches. William C. Brown, Dubuque (1981)

Petty, R.E., Cacioppo, J.T.: Communication and Persuasion: Central and Peripheral Routes to Attitude Change. Springer, New York (1986)

Petty, R.E., Fazio, R.H., Brinol, P. (eds.): Attitudes: Insights from the New Implicit Measures. Psychology Press, Taylor and Francis Group, New York (2009)

Petty, R.E., Krosnick, J.A.: Attitude strength: an overview, chapter 1. In: Petty, R.E., Krosnick, J.A. (eds.), Attitude Strength: Antecedents and Consequences. Psychology Press, New York, pp 1-23 ([1995] 2014)

Pickel, A.: Rethinking systems theory. A programmatic introduction. Philos. Soc. Sci. 37(4), 391-407 (2007)

Poli, R.: The basic problem of the theory of levels of reality. Axiomathes 12(3-4), 261-283 (2001)

Poli, R.: First steps in experimental phenomenology. In: Loula, A., Gudwin, R., Queiroz, J. (eds.) Artificial Cognition Systems, pp. 358-386. Idea Group Publishing, Hersey (2006)

Pomerantz, E.M., Chaiken, S., Tordesillas, R.S.: Attitude strength and resistance processes. J. Pers. Soc. Psychol. 69, 408-419 (1995)

Pye, L.W.: Culture and political science: problems in the evaluation of the concept of political culture. In: Schneider, L., Bonjean, C.M. (eds.) The Idea of Culture in the Social Sciences. Cambridge University Press, Cambridge, pp. 65-76 (1973)

Rhodes, R.A.W., Bevir, M.: The State as Cultural Practice. Oxford University Press, Oxford (2010)

Rhodes, R.A.W., Bevir, M.: Interpreting British Governance. Routledge, London New York (2003)

Rokeach, M. (ed.): Understanding Human Values. Free Press, New York (1979)

Rokeach, M., Kliejunas, P.: Behavior as a function of attitude-toward-object and attitude-toward-situation. J. Pers. Soc. Psychol. 22, 194-201 (1972)

Rose, R.: Post-communist political transformation in central and eastern Europe. In: Political Change and Welfare Development in Central and Eastern Europe. Österreichische Gesellschaft für Europapolitik, Vienna, pp. 11-36 (1998a)

Rose, R.: Prospects for democracy in post-communist Europe. In: White, S., Batt, J., Lewis, P.G. (eds.) Developments in Central and East European Politics, 2nd edn, pp. 276-295. Macmillan and Duke University Press, London (1998b)

Rose, R., Mishler, M., Haerpfer, C.: Democracy and Its Alternatives: Understanding Post-Communist Societies. Johns Hopkins University Press, Baltimore (1998)

Rosen, R.: Anticipatory Systems. Pergamon Press, Oxford (1985)

Rosenberg, M.J., Hovland, C.I.: Cognitive, affective, and behavioral components of attitudes, Chapter 1. In: Rosenberg, M.J., Hovland, C.I., McGuire, W.J., Abelson, R.P., Brehm, J.W. (eds.) Attitude Organization and Change. An Analysis of Consistency Among Attitude Components, pp. 1-15. Yale University Press, New Haven (1960)

Sakamoto, T.: Conflict analysis in virtual states (CAVS): a new experimental method based on the extensive use of multi-agent simulation (MAS) and geographical information system (GIS). JICA-RI WP 56, 1-27 (2013)

Sawyer, R.K.: The mechanisms of emergence. Philos. Soc. Sci. 34(2), 260-282 (2004)

Schmitter, P.C., Schneider, C.Q.: Liberalization, transition and consolidation: measuring the components of democratization. In: Croissant, A., Merkel, W. (eds.), Democratization, Special Issue: Consolidated or Defective Democracy? Problems of Regime Change, vol. 11, No. 5, pp. 59-90 (2004)

Schwartz, S.H.: Universals in the content and structure of values: theory and empirical tests in 20 countries. In: Zanna, M. (ed.) Advances in Experimental Social Psychology, vol. 25, pp. 1-65. Academic Press, New York (1992)

Schwartz, S.H.: An overview of the schwartz theory of basic values. Online Read. Psychol. Culture, 2(1) (2012). https://doi.org/10.9707/2307-0919.1116

Schwartz, S., Bardi, A.: Influences of adaptation to communist rule on value priorities in Eastern Europe. Polit. Psychol. 18(2), 385-410 (1997)

Sullivan, J.L., Rahn, W.M., Rudolph, T.: The contours of political psychology: situating research on political information processing, part I, chap, 1. In: Kuklinski, J.H. (Ed.) Thinking about Political Psychology. Cambridge University Press, pp. 23-47 (2009)

Steinmetz, G.: Introduction: culture and the state. In: Steinmetz, G. (ed.) State/Culture: State-Formation after the Cultural Turn, pp. 1-49. Cornell University Press, Ithaca (1999) 
Taber, C.S., Timpone, R.J.: Computational Modeling, Sage University Paper Series on Quantitative Applications in the Social Sciences. Sage, Newbury Park (1996)

Thompson, M., Verweij, M., Ellis, R.J.: Why and how culture matters?, Chap. 17. In: Goodin, R.E., Tilly, C. (eds.) The Oxford Handbook of Contextual Political Analysis. Oxford University Press, pp. 319-340 (2006)

Tilly, C.: From Mobilization to Revolution. Addison-Wesley, Reading (1978)

Tilly, C.: To explain political processes. Am. J. Sociol. 100(6), 1594-1610 (1995)

Tilly, C.: Epilogue: Now where? In: Steinmetz, G. (ed.) State/Culture: State-Formation After the Cultural Turn, pp. 407-420. Cornell University Press, Ithaca (1999)

Tilly, Ch.: Mechanisms in political processes. Annu. Rev. Polit. Sci. 4, 21-41 (2001)

Urbig, D.: Attitude dynamics with limited verbalisation capabilities. J. Artif. Soc. Soc. Simul. 6(1), 1-23 (2003)

Urbig, D., Malitz, R.: Drifting to more extreme but balanced attitudes: Multidimensional attitudes and selective exposure. Conference paper, ESSA Conference, Toulouse (2007)

Voinea, C.F.: Computational modelling and simulation of attitude change part 1: connectionist models and simulations of cognitive dissonance. An Overview. Eur. Q. Polit. Attitudes Ment. EQPAM 2(3), 10-26 (2013)

Voinea, C.F.: On mechanism, process and polity: an agent-based modeling and simulation approach. Eur. Q. Polit. Attitudes Ment. 3(3), 15-45 (2014)

Voinea, C.F.: Political Attitudes: Computational and Simulation Modelling. Wiley, Chichester (2016)

Weber, M.: The methodology of the social sciences, Shils, E.A., Finch, H.A. (eds., trans.). Free Press, New York (1949)

Welch, S.: The Political Culture Theory. Oxford University Press, Oxford (2013)

Welzel, C.: Political culture, Chapter 16. In: Landman, T., Robinson, N. (eds.) The SAGE Handbook of Comparative Politics, pp. 299-318. SAGE Publications Ltd, Thousand Oaks (2009)

Wilson, T.D., Hodges, S.D.: Attitudes as temporary constructions. In: Martin, L.L., Tesser, A. (eds.) The Construction of Social Judgments, pp. 37-65. Erlbaum, Hillsdale (1992)

Wilson, T.D., Lindsey, S., Schooler, T.Y.: A model of dual attitudes. Psychol. Rev. 107, 101-126 (2000)

Woelfel, J., Cody, M.J., Gillham, J.R., Holmes, R.: Basic premises of multi-dimensional attitude change theory. Hum. Commun. Res. 6, 153-167 (1980)

Yamakage, S. with collaboration of: Hoshiro Hiroyuki, Mitsutsuji Katsuma, Sakamoto Takuto, Suzuki Kazutoshi, and Yamamoto Kazuya (2005) Political Science and Multi-Agent Simulation: Affinities, Examples and Possibilities, Fourth International Workshop on Agent-based Approaches in Economic and Social Complex Systems/Annual Conference of Pacific-Asian Association for Agent-based Approach in Social Sciences, July 9-13, 2005, at Tokyo Institute of Technology

Publisher's Note Springer Nature remains neutral with regard to jurisdictional claims in published maps and institutional affiliations. 